\title{
A study on selective transformation of norbornadiene into fluorinated cyclopentane-fused isoxazolines
}

\author{
Zsanett Benke ${ }^{1,2}$, Attila M. Remete ${ }^{1,2}$ and Loránd Kiss ${ }^{* 1,2, \S}$
}

\author{
Full Research Paper \\ Address: \\ ${ }^{1}$ Institute of Pharmaceutical Chemistry, University of Szeged, H-6720 \\ Szeged, Eötvös u. 6, Hungary and ${ }^{2}$ University of Szeged, \\ Interdisciplinary Excellence Centre, Institute of Pharmaceutical \\ Chemistry, H-6720 Szeged, Eötvös u. 6, Hungary \\ Email: \\ Loránd Kiss* - kiss.lorand@szte.hu \\ * Corresponding author \\ § Tel: +36-30-8535341 \\ Keywords: \\ functionalization; metathesis; nitrile oxide; organofluorine chemistry; \\ selectivity \\ Beilstein J. Org. Chem. 2021, 17, 2051-2066. \\ https://doi.org/10.3762/bjoc.17.132 \\ Received: 18 May 2021 \\ Accepted: 31 July 2021 \\ Published: 13 August 2021 \\ Associate Editor: I. Marek \\ (C) 2021 Benke et al.; licensee Beilstein-Institut. \\ License and terms: see end of document.
}

\begin{abstract}
This work presents an examination of the selective functionalization of norbornadiene through nitrile oxide 1,3-dipolar cycloaddition/ring-opening metathesis (ROM)/cross-metathesis (CM) protocols. Functionalization of commercially available norbornadiene provided novel bicyclic scaffolds with multiple stereogenic centers. The synthesis involved selective cycloadditions, with subsequent ROM of the formed cycloalkene-fused isoxazoline scaffolds and selective CM by chemodifferentiation of the olefin bonds of the resulting alkenylated derivatives. Various experimental conditions were applied for the CM transformations with the goal of exploring substrate and steric effects, catalyst influence and chemodifferentiation of the olefin bonds furnishing the corresponding functionalized, fluorine-containing isoxazoline derivatives.
\end{abstract}

\section{Introduction}

Olefin metathesis is considered to be a powerful synthetic tool for the creation of olefin bonds [1]. Several types of metathesis reactions, such as ring-opening metathesis (ROM), cross-metathesis $(\mathrm{CM})$, ring-closing metathesis (RCM) or ring-opening/ cross-metathesis (ROCM) have found high utility in the creation of $\mathrm{C}=\mathrm{C}$ bonds and in the synthesis of a number of organic molecules, functionalized scaffolds or various building blocks. The efficient catalytic activity and remarkable functional group tolerance of commercially available versatile Ru-based olefin metathesis catalysts have allowed wide applica-

bility of these transformations [1-8]. Moreover, the robustness of many commercial Ru-based catalysts has enabled the general application of olefin metathesis in the synthesis of versatile functionalized heterocycles [9-11], a wide variety of natural products (especially macrocycles) [12], alkaloids [13], amino acids and functionalized biomolecules such as peptides [14-20] or various drugs [21]. Due to the ring strain, bicyclic systems and derivatives, such as norbornadiene derivatives can easily be converted across ROM or ROCM into a variety of alkenylated, functionalized scaffolds [22-34]. Although metathesis is a re- 
versible process, it is often shifted towards a certain direction. For example, the equilibrium of the reaction of ethylene with a strained ring system and the corresponding ROM product is shifted towards ROM because ring strain disfavors reclosing of the ring system. Therefore, functionalized norbornenes, which are highly strained scaffolds, easily provide a number of functionalized cyclopentanes across the ROM/CM process.

It is well known that the structure of a certain metathesis substrate, the nature of the catalyst and all experimental conditions may highly influence metathesis reactions and determine the outcome of olefin metathesis. The accurate prediction of a specific catalyst, including its efficiency, the suitable experimental conditions such as catalyst loading, temperature, solvent, reaction time or even work-up seem to be a difficult task. It is observed that there is no single universal catalyst suitable for all types of metathesis reactions, and there is no general relationship between the structure of the substrate and the type of catalyst. These assumptions might be valid, in particular, for selective processes such as selection between the olefin bonds by chemodifferentiation or chemodiscrimination [1-8,22].

Since the nature of the substrate, catalyst as well as reaction conditions affect the outcome of metathesis, various publications were dedicated to studies describing selective CM or ROCM transformations. The accurate prediction of selectivity regarding $\mathrm{CM}$ reactions is still considered to be a challenging issue among synthetic organic chemists. Of numerous factors contributing to the observed selectivities in metathesis reactions, H-bonding interactions between chloride ligands as $\mathrm{H}$-bond acceptors and $\mathrm{OH}$ or $\mathrm{NH}$ functions in the metathesis intermediate appear to be determining $[35,36]$.

Selectivity derived from chelation is considered to be an another important contributor. Through the formation of intermediates with stable (e.g., six-membered) chelate ring systems, the chelation ability of oxygen functionalities to ruthenium during metathesis can greatly influence the outcome of the CM reaction $[36,37]$. Steric factors are another important phenomenon, which will possibly contribute to the selectivity of olefin bonds during a CM reaction [38-43].

Investigations of various types of olefins in $\mathrm{CM}$, such as substituted and functionalized styrenes, unsaturated tertiary alcohols, olefins with quaternary carbon centers, acrylates, allyl ethers or allyl acetates gave a general model suitable for the prediction of product selectivity and olefin bond chemodifferentiation in cross metathesis. In general, regarding the reactivity of the olefin bond in $\mathrm{CM}$, alkenes can be categorized by the relative ability to undergo homodimerization via $\mathrm{CM}$ and the possibility of the corresponding homodimers for novel secondary me- tathesis reactions [44]. Thus, olefins can be categorized as type I (fast homodimerization), type II (slow homodimerization), type III (no homodimerization) and type IV (unreactive olefins, spectators to $\mathrm{CM}$ ) [44].

Although olefins with perfluorinated alkane moiety are considered as to be of type II, only a handful of literature data are available on the behavior of fluorine-containing olefins or perfluorinated alkenes. The incorporation of fluoroalkyl moieties (such as difluoromethyl, trifluoromethyl and perfluoroalkyl groups) into an organic molecule can often enhance the pharmacokinetic properties of lead candidates in drug research through the improvement in lipophilicity, absorption, distribution, hydrophobicity and metabolism. Considering the high importance of organofluorine chemistry and that of fluoroalkyl groups in pharmaceutical chemistry, a wide range of novel and efficient protocols for the introduction of fluorinated scaffolds or fluoroalkyl groups onto organic molecular entities represent a hot topic in synthetic organic chemistry [45-48]. In order to prepare a certain fluorinated organic molecule, two common approaches are used: i) late-stage fluorination, when the fluorine atom is incorporated in the final step of the synthetic protocol (e.g., deoxofluorinations) or ii) application of various commercial fluorine-containing scaffolds (e.g., fluorine-containing amines, fluorine-containing alkenes etc.) [49-58]. It is to be noted that a recent review has been devoted to the synthesis of various fluorine-containing derivatives through various metathesis techniques by the application of versatile fluorinated substrates [59].

\section{Results and Discussion}

The aim of the current work was to investigate the selective functionalization of readily available norbornadiene across nitrile oxide cycloaddition/ROM/CM protocols in view of the access of various fluorine-containing molecular entities as well as to explore the chemical behavior of olefin bonds in the reaction with some fluorinated alkene derivatives in view of chemodifferentiation. The reactions were performed with various olefin metathesis catalysts to find the most optimal conditions (Figure 1).

The starting divinyl-substituted bicyclic isoxazolines were synthesized according to literature methods, as shown in Figure 2, utilizing nitrile oxide cycloaddition according to the Mukaiyama method followed by ROM of the major product. All five catalysts provided the desired products to some extent, but HG-1 gave the highest yield of ( \pm -4: $76 \%,( \pm)-5: 75 \%$ and (土)-6: $87 \%[41]$.

Further functionalization of compounds ( \pm )-4-6 was attempted via $\mathrm{CM}$ with a high number of fluorine-containing alkenes 


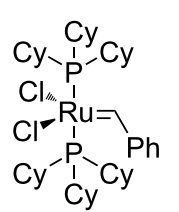

Grubbs

1st generation (G-1)

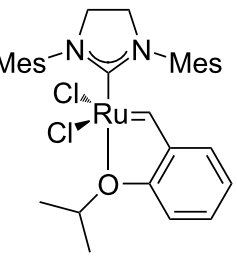

Hoveyda-Grubbs 2nd generation (HG-2)

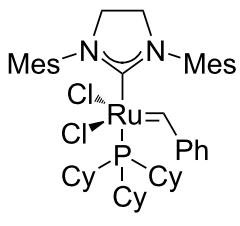

Grubbs 2nd generation

(G-2)

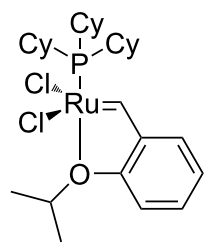

Hoveyda-Grubbs 1st generation (HG-1)
Figure 1: Some commercial Ru-based catalysts used in the current work.

(Figure 3). Compounds $\mathbf{7 a}$ and $\mathbf{7 b}$ as well as $\mathbf{7 f}-\mathbf{h}$ were type I olefins, while acrylate esters $\mathbf{7 c}-\mathbf{e}$ were type II olefins. Because 1 st generation metathesis catalysts usually perform poorly in $\mathrm{CM}$ reactions with acrylates [31,32,36,39,41], only G-2, HG-2 and G-3 were used in our CM steps.

CM reactions of compound $( \pm)-\mathbf{4}$ were investigated first. With 4-bromo-3,3,4,4-tetrafluorobut-1-ene and allyl 2,2,2-trifluoroacetate, no CM product was observed. However, CM reactions with 1,1,1,3,3,3-hexafluoropropan-2-yl acrylate (7c) were successful (Scheme 1 and Table 1). When catalyst HG-2 was used (Table 1, entries 1 and 2), decomposition of the catalyst with
$\mathrm{NaHCO}_{3}$ in aqueous $\mathrm{MeOH}$ during workup improved the yield. Therefore, catalyst decomposition was incorporated into the workup procedure of all other CM reactions.

The outcome of the reaction between $( \pm)-\mathbf{4}$ and $\mathbf{7 c}$ was catalystdependent (Table 1). In the presence of HG-2, the main product was dicoupled $( \pm)-8 \mathbf{c}$ accompanied by the unseparable mixture of monocoupled products $( \pm)-\mathbf{8 a}$ and $( \pm)-\mathbf{8 b}$. Despite the partial signal overlap, 2D NMR analysis of the $( \pm)-\mathbf{8 a}$ and $( \pm)-\mathbf{8 b}$ mixture was possible, and the structure of both $( \pm)-\mathbf{8 a}$ and $( \pm)-\mathbf{8 b}$ as well as the compound ratio could be determined. When catalyst G-2 or G-3 was applied for the CM reaction, only monocoupled products were formed. Notably, G-2 or G-3 catalysts had lower selectivity towards $( \pm)-\mathbf{8 a}$ (ratio of $( \pm)-\mathbf{8 a}$ and $( \pm)-\mathbf{8 b}$ : 3.3:1 with HG-2 and 2.5:1 with G-2 or G-3), but they, in particular G-2, provided a superior combined yield of $( \pm)-\mathbf{8 a}$ and $( \pm)-8 \mathbf{b}$.

Note, that although the yield of the CM is relatively low, a full conversion of the starting isoxazoline could be detected. However, all CM transformations alongside the desired coupled compounds afforded a significant amount of unidentifiable polymeric material.

CM reactions of compound ( \pm )-4 with 2,2,3,3,4,4,4-heptafluorobutyl acrylate (7d) were also successful (Scheme 2 and Table 2). Again, the catalyst HG-2 provided mainly the dimetathesized product. CM in the presence of G-2 or G-3 gave mainly an inseparable mixture of monometathesized products, but some dimetathesized $( \pm)-9 \mathrm{c}$ was formed too. Similar to Table 1, G-2 provided the highest combined yield of ( \pm )-9a and $( \pm)-9 \mathbf{b}$, but it was the least regioselective (ratio of $( \pm)-9 \mathbf{a}$ and $( \pm)-9$ b: $3.3: 1$ with HG-2, 2.5:1 with G-3 and 2:1 with G-2).

We continued our investigation with $\mathrm{CM}$ reactions of compound ( \pm )-4 with 2,2,2-trifluoroethyl acrylate (7e, Scheme 3

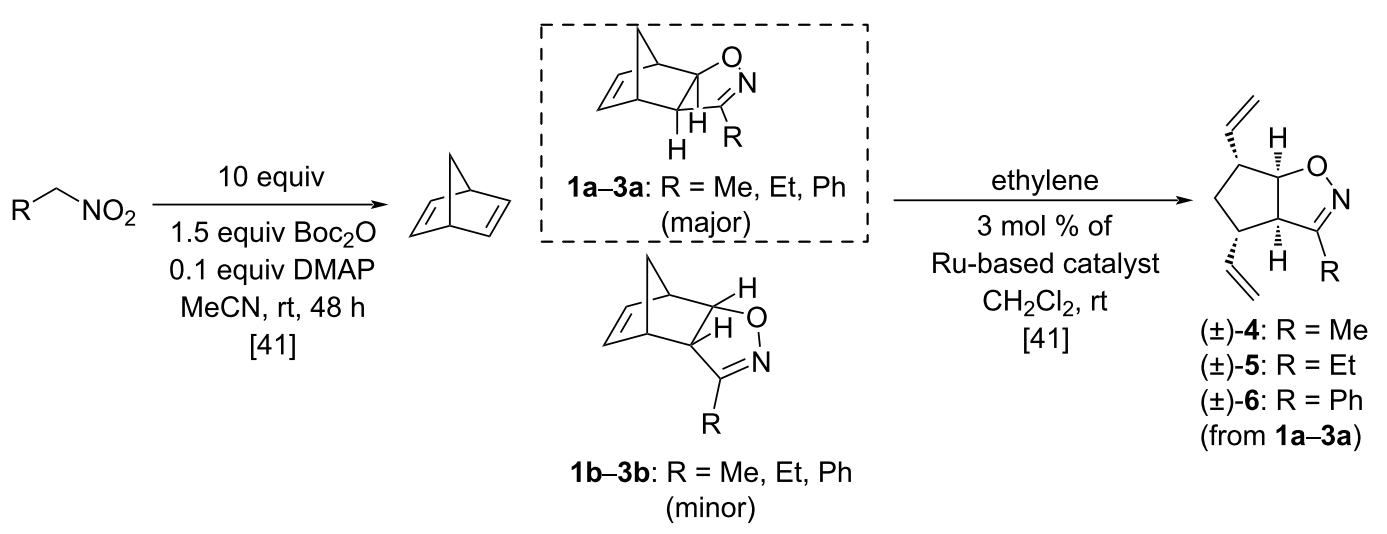

Figure 2: Synthesis of divinylated cyclopentane-fused isoxazolines [41]. 
<smiles>C=CC(F)(F)C(F)(F)Br</smiles>

4-bromo-3,3,4,4-tetrafluorobut-1-ene (7a)<smiles>C=CCOC(=O)C(F)(F)F</smiles>

allyl 2,2,2-trifluoroacetate (7b)<smiles>C=CC(=O)OC(C(F)(F)F)C(F)(F)F</smiles>

1,1,1,3,3,3-hexafluoropropan-2-yl acrylate (7c)<smiles>C=CC(=O)OCCC(F)(F)C(F)(F)F</smiles>

2,2,3,3,4,4,4-heptafluorobutyl acrylate (7d)<smiles>C=CC(=O)OCC(F)(F)F</smiles>

2,2,2-trifluoroethyl acrylate (7e)<smiles>C=CCC(O)(C(F)(F)F)C(F)(F)F</smiles>

1,1,1-trifluoro-2-(trifluoromethyl)pent-4-en-2-ol (7f)<smiles>C=CCOCCC(F)CC(F)CC(F)C(F)(F)F</smiles>

8-(allyloxy)-1,1,1,2,2,3,3,4,4,5,5,6,6-tridecafluorooctane (7g)<smiles>C=Cc1ccc(F)cc1</smiles>

4-fluorostyrene $(7 \mathrm{~h})$ type I (fast homodimerization)

type I (fast homodimerization)

type II (slow homodimerization)

type II (slow homodimerization)

type II (slow homodimerization)

type I (fast homodimerization)

type I (fast homodimerization)

type I (fast homodimerization)

Figure 3: Various fluorine-containing olefins used in the current work.

and Table 3). Interestingly, even with HG-2 catalyst, dicoupled product $( \pm)-10$ c formed only in trace amounts. With G-2 and G-3 catalysts, only monocoupled products $( \pm)-\mathbf{1 0 a}$ and $( \pm)-\mathbf{1 0 b}$ were formed as an inseparable mixture. Similar to Table 1, HG-2 provided the lowest combined yield of monocoupled products, but it had the highest regioselectivity (ratio of $( \pm)$-10a and ( \pm )-10b: $3.3: 1$ with HG-2 and 1.66:1 with G-2 and G-3, respectively). The highest yield for the $( \pm)-\mathbf{1 0 a}$ and $( \pm)-\mathbf{1 0 b}$ mixture $(23 \%)$ was achieved with G-2 catalyst.
Then, substrate $( \pm)-\mathbf{4}$ was subjected to $\mathrm{CM}$ with type I olefin $\mathbf{7 f}$ utilizing HG-2 and G-2 catalysts (Scheme 4 and Table 4). As shown in Tables 1-3, G-3 gave similar or slightly inferior yield compared to G-2. To our surprise, dimetathesized product $( \pm)$-11c was not formed, and the two monometathesized products were separable. Interestingly, regioselectivity was reversed compared to those in Tables 1-3: the main product was ( \pm )-11b (26\% with HG-2, 25\% with G-2), while isomeric product $( \pm)$-11a was formed in lower yield (15\% with HG-2 and 

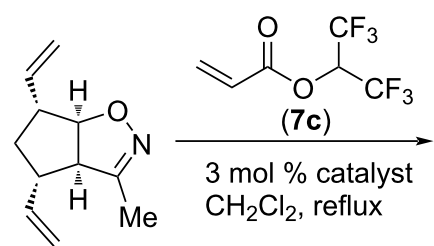

$( \pm)-4$<smiles>C=C[C@H]1C[C@H](/C=C/C(=O)OC(C(F)(F)F)C(F)(F)F)[C@H]2ON=C(C)[C@H]12</smiles>

$( \pm)-8 a$<smiles>C=CC1CC(/C=C/C(=O)OC(F)(F)F)C2C([N+](=O)[O-])=NOC12</smiles>

$( \pm)-8 b$

(minor)

mixture of monometathesized products

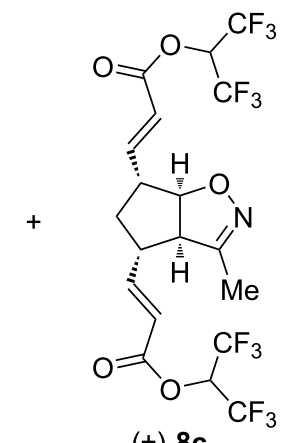

$( \pm)-8 c$

Scheme 1: Cross-metathesis of divinylated isoxazoline ( \pm )-4 with 1,1,1,3,3,3-hexafluoropropan-2-yl acrylate (7c).

Table 1: CM of isoxazoline ( \pm )-4 with 1,1,1,3,3,3-hexafluoropropan-2-yl acrylate (7c).

\begin{tabular}{|c|c|c|c|c|}
\hline entry & catalyst & reaction time & yield and ratio of $( \pm)-\mathbf{8 a}$ and $( \pm)-\mathbf{8 b}$ & yield of $( \pm)-8 c$ \\
\hline 1 & HG-2 & $5 \mathrm{~h}$ & $5 \%(3.3: 1)$ & $16 \%{ }^{a}$ \\
\hline 2 & HG-2 & $5 \mathrm{~h}$ & $10 \%(3.3: 1)$ & $17 \%$ \\
\hline 3 & G-3 & $5 \mathrm{~h}$ & $15 \%(2.5: 1)$ & $0 \%$ \\
\hline 4 & G-2 & $5 \mathrm{~h}$ & $25 \%(2.5: 1)$ & $0 \%$ \\
\hline
\end{tabular}

a $\mathrm{MeOH}, \mathrm{H}_{2} \mathrm{O} / \mathrm{NaHCO}_{3}$ were not added before concentration of the mixture. Note: all yields reported in tables are isolated yield values.

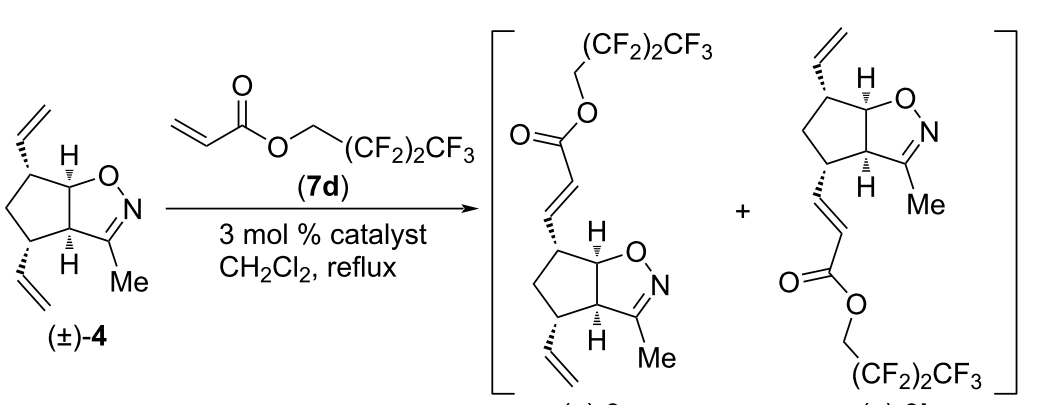

$( \pm)-9 a$

(major)

$( \pm)-9 b$

(minor)

mixture of monometathesized products

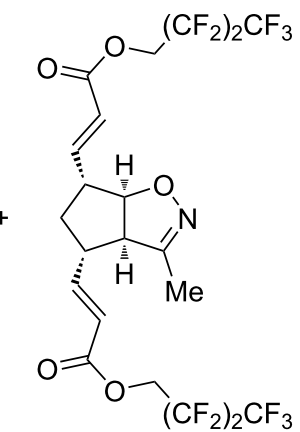

$( \pm)-9 c$

Scheme 2: Cross-metathesis of divinylated isoxazoline ( \pm )-4 with $2,2,3,3,4,4,4$-heptafluorobutyl acrylate (7d).

Table 2: CM of isoxazoline ( \pm )-4 with 2,2,3,3,4,4,4-heptafluorobutyl acrylate (7d).

\begin{tabular}{|c|c|c|c|c|}
\hline entry & catalyst & reaction time & yield and ratio of $( \pm)-9 a$ and $( \pm)-9 b$ & yield of $( \pm)-9 c$ \\
\hline 1 & HG-2 & $5 \mathrm{~h}$ & $20 \%(3.3: 1)$ & $34 \%$ \\
\hline 2 & G-3 & $5 \mathrm{~h}$ & $11 \%(2.5: 1)$ & trace \\
\hline 3 & G-2 & $5 \mathrm{~h}$ & $36 \%(2: 1)$ & $10 \%$ \\
\hline
\end{tabular}




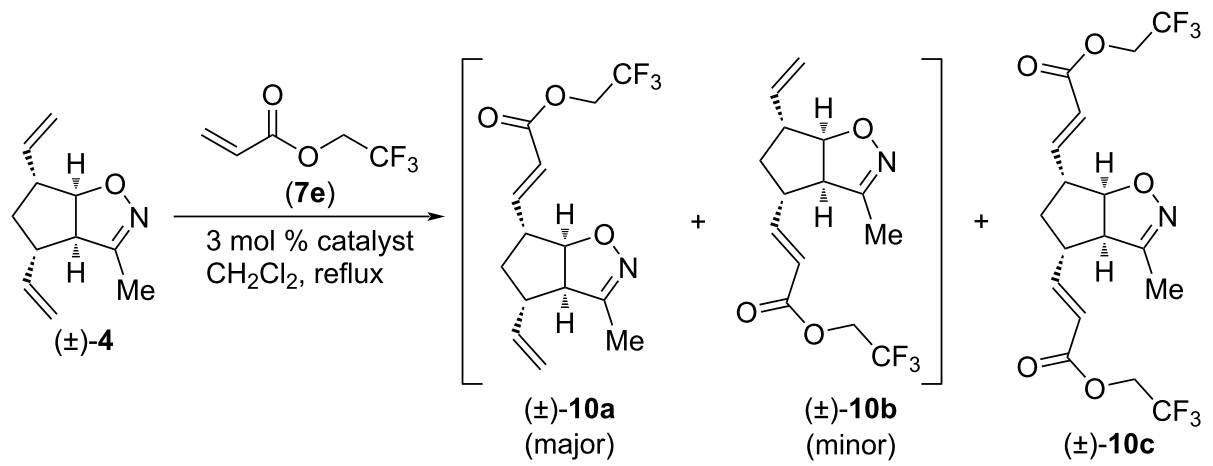

mixture of monometathesized products

Scheme 3: Cross-metathesis of divinylated isoxazoline ( $\mathbf{\pm})-\mathbf{4}$ with 2,2,2-trifluoroethyl acrylate (7e).

Table 3: CM of isoxazoline ( \pm )-4 with 2,2,2-trifluoroethyl acrylate (7e).

$\begin{array}{lllll}\text { entry } & \text { catalyst } & \text { reaction time } & \text { yield and ratio of }( \pm)-10 a \text { and }( \pm)-10 b & \text { yield of }( \pm)-10 c \\ 1 & \text { HG-2 } & 5 \mathrm{~h} & 15 \%(3.3: 1) & \text { trace } \\ 2 & \text { G-3 } & 5 \mathrm{~h} & 19 \%(1.66: 1) & 0 \% \\ 3 & \text { G-2 } & 5 \mathrm{~h} & 23 \%(1.66: 1) & 0 \%\end{array}$<smiles>C=C[C@@H]1C[C@H](C=C)C2C([N+](=O)[O-])=NO[C@@H]21</smiles>

$( \pm)-4$

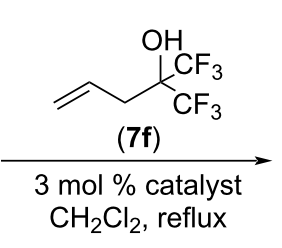<smiles>C=CC1CC(/C=C/CC(O)(F)F)C2ON=C(C)C12</smiles>

$( \pm)-11 a$

(minor)

eparated monometathesized products

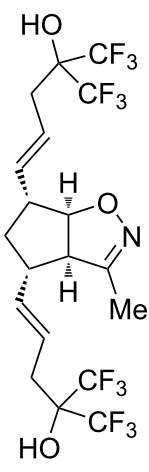

$( \pm)-11 c$

Scheme 4: Cross-metathesis of divinylated isoxazoline ( \pm )-4 with 1,1,1-trifluoro-2-(trifluoromethyl)pent-4-en-2-ol (7f).

Table 4: CM of isoxazoline ( \pm )-4 with 1,1,1-trifluoro-2-(trifluoromethyl)pent-4-en-2-ol (7f).

$\begin{array}{llllll}\text { entry } & \text { catalyst } & \text { reaction time } & \text { yield of }( \pm)-\mathbf{1 1 a} & \text { yield of }( \pm)-11 b & \text { yield of }( \pm)-11 c \\ 1 & \text { HG-2 } & 5 \mathrm{~h} & 15 \% & 26 \% & 0 \% \\ 2 & \text { G-2 } & 5 \mathrm{~h} & 10 \% & 25 \% & 0 \%\end{array}$

$10 \%$ with G-2). G2 catalyst showed better regioselectivity (ratio of $( \pm)-\mathbf{1 1 a}$ and $( \pm)-\mathbf{1 1 b}: 1: 1.73$ with $\mathrm{HG}-2$ and $1: 2.5$ with G-2).
Next, CM reactions of isoxazoline $( \pm)-\mathbf{4}$ with type I olefin $\mathbf{7 g}$ were studied (Scheme 5 and Table 5) applying HG-2 and G-2 catalysts. Under these conditions, dicoupled product $( \pm)-\mathbf{1 2 c}$ 


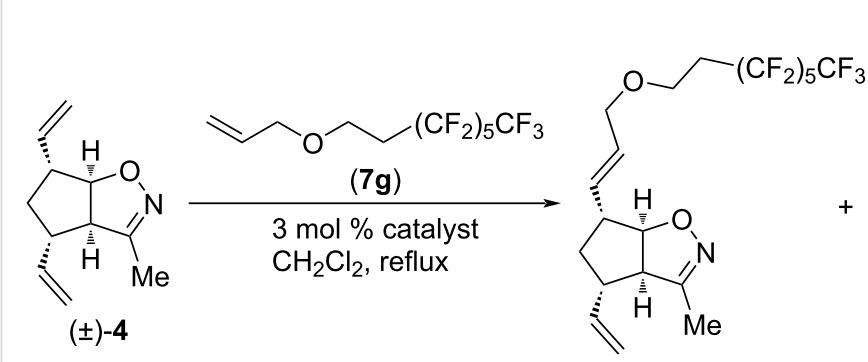

$( \pm)-12 a$

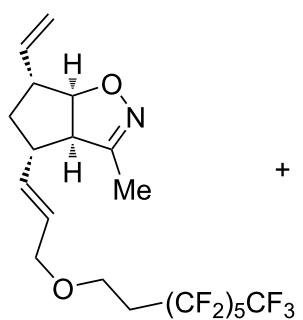

$( \pm)-12 b$

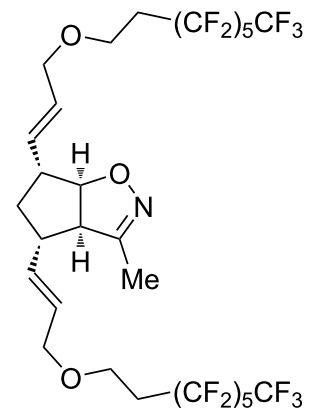

$( \pm)-12 c$

Scheme 5: Cross-metathesis of divinylated isoxazoline ( \pm )-4 with 8-(allyloxy)-1,1,1,2,2,3,3,4,4,5,5,6,6-tridecafluorooctane (7g).

Table 5: CM of isoxazoline ( \pm )-4 with 8-(allyloxy)-1,1,1,2,2,3,3,4,4,5,5,6,6-tridecafluorooctane (7g).

\begin{tabular}{|c|c|c|c|c|c|}
\hline entry & catalyst & reaction time & yield of $( \pm)-12 a$ & yield of $( \pm)-12 b$ & yield of $( \pm)-12 c$ \\
\hline 1 & HG-2 & $5 \mathrm{~h}$ & $9 \%$ & $6 \%$ & $0 \%$ \\
\hline 2 & G-2 & $5 \mathrm{~h}$ & $3 \%$ & $5 \%$ & $0 \%$ \\
\hline
\end{tabular}

was not detected. The formed monocoupled products $( \pm)-\mathbf{1 2 a}$ and $( \pm)-\mathbf{1 2 b}$ were separable. HG-2 provided both $( \pm)-\mathbf{1 2 a}$ and $( \pm)$-12b in better yield. Interestingly, $( \pm)-\mathbf{1 2 a}$ was the main product with HG-2, and $( \pm)-\mathbf{1 2 b}$ with G-2.
In the final test of compound ( \pm )-4, it was subjected to $\mathrm{CM}$ with 4-fluorosryrene (7h), a type I olefin (Scheme 6 and Table 6). With HG-2 catalyst, the main product was dicoupled ( \pm )-13c, while the minor product was an inseparable mixture of mono-<smiles>C=C[C@@H]1C[C@H](C=C)[C@H]2ON=C(C)[C@H]12</smiles>

$( \pm)-4$

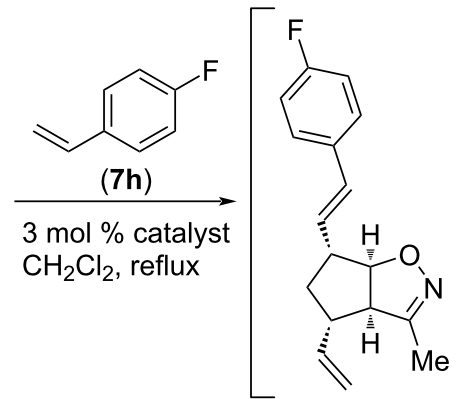

$( \pm)-13 a$
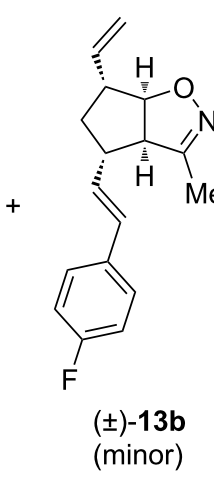

$( \pm)-13 b$

(minor) mixture of monometathesized products

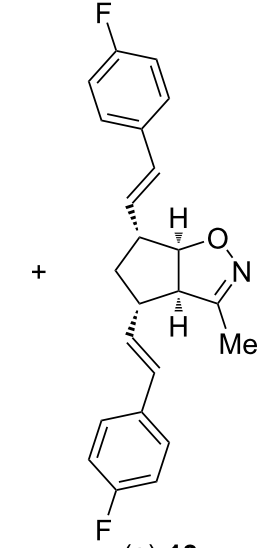

$( \pm)-13 c$

Scheme 6: Cross-metathesis of divinylated isoxazoline ( \pm )-4 with 4-fluorostyrene (7h).

Table 6: $\mathrm{CM}$ of isoxazoline ( \pm )-4 with 4-fluorostyrene (7h).

$\begin{array}{lllll}\text { entry } & \text { catalyst } & \text { reaction time } & \text { yield and ratio of }( \pm)-\mathbf{1 3 a} \text { and }( \pm)-\mathbf{1 3 b} & \text { yield of }( \pm)-\mathbf{1 3 c} \\ 1 & \text { HG-2 } & 5 \mathrm{~h} & 18 \%(1.4: 1) & 30 \% \\ 2 & \text { G-3 } & 5 \mathrm{~h} & 28 \%(1.4: 1) & 5 \% \\ 3 & \text { G-2 } & 5 \mathrm{~h} & 36 \%(1.4: 1) & 12 \%\end{array}$


coupled products $( \pm)-\mathbf{1 3 a}$ and $( \pm)-\mathbf{1 3 b}$. When G-2 or G-3 catalyst, respectively, was applied for the CM reaction, the major product mixture was $( \pm)$-13a and $( \pm)-\mathbf{1 3 b}$ (the best yield was achieved with G-2) accompanied by some ( \pm )-13c. Interestingly, regioselectivity of all three catalysts was the same, with a 1.4:1 ratio of $( \pm)-\mathbf{1 3 a}$ and $( \pm)-\mathbf{1 3 b}$.

We continued our work with the study of CM reactions of compound $( \pm)-5$, which has a slightly longer alkyl chain on the heteroring compared to that of ( \pm )-4. Similar to $( \pm)-4$, no CM product was observed with olefins $\mathbf{7 a}$ and $\mathbf{7 b}$. In contrast, CM reactions with 7c were successful (Scheme 7 and Table 7). With
HG-2 catalyst, dimetathesized compound $( \pm)-\mathbf{1 4 c}$ was the main product, and some monometathesized $( \pm)$-14a was also formed. With G-2 catalyst, the outcome was the opposite. Interestingly, G-3 catalyst provided only an inseparable mixture of monometathesized products $( \pm)-\mathbf{1 4 a}$ and $( \pm)-\mathbf{1 4 b}$ (note, that compound ( \pm -14b was not formed in the presence of HG-2 or G-2).

CM reactions of isoxazoline ( \pm )-5 with olefin $\mathbf{7 d}$ in the presence of G-3 catalyst led to the inseparable mixture of monocoupled products $( \pm)-\mathbf{1 5 a}$ and $( \pm)-\mathbf{1 5 b}$ (Scheme 8 and Table 8$)$. With G-2 catalyst, a mixture of ( \pm )-15a and ( \pm )-15b was formed

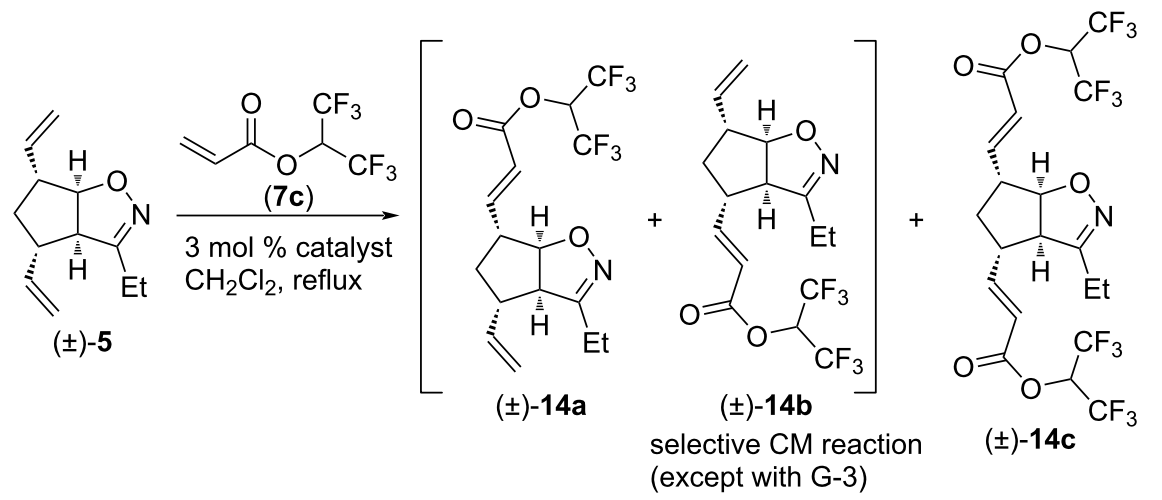

Scheme 7: Selective CM of divinylated isoxazoline ( \pm )-5 with 1,1,1,3,3,3-hexafluoropropan-2-yl acrylate (7c).

Table 7: CM of isoxazoline ( \pm )-5 with 1,1,1,3,3,3-hexafluoropropan-2-yl acrylate (7c).

\begin{tabular}{|c|c|c|c|c|}
\hline entry & catalyst & reaction time & yield and ratio of $( \pm)-14 a$ and $( \pm)-14 b$ & yield of $( \pm)-14 c$ \\
\hline 1 & HG-2 & $5 \mathrm{~h}$ & $2 \%(1: 0)$ & $27 \%$ \\
\hline 2 & G-3 & $5 \mathrm{~h}$ & $13 \%(2: 1)$ & $0 \%$ \\
\hline 3 & G-2 & $5 \mathrm{~h}$ & $16 \%(1: 0)$ & $7 \%$ \\
\hline
\end{tabular}

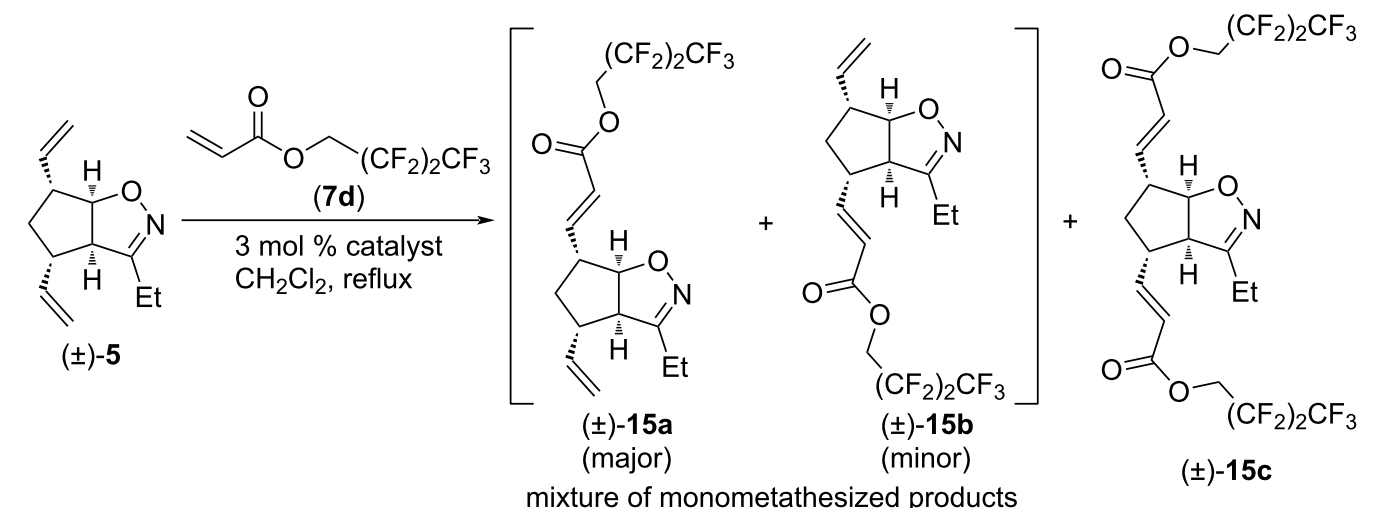


Table 8: CM of isoxazoline ( \pm )-5 with 2,2,3,3,4,4,4-heptafluorobutyl acrylate (7d).

\begin{tabular}{lllll} 
entry & catalyst & reaction time & yield and ratio of $( \pm)-\mathbf{1 5 a}$ and $( \pm)-\mathbf{1 5 b}$ & yield of $( \pm)-\mathbf{1 5 c}$ \\
\hline 1 & HG-2 & $5 \mathrm{~h}$ & $9 \%(5: 1)$ & $0 \%$ \\
2 & G-3 & $5 \mathrm{~h}$ & $8 \%(2: 1)$ & $18 \%$ \\
3 & G-2 & $5 \mathrm{~h}$ & $34 \%(3.3: 1)$ &
\end{tabular}

in significantly higher yield, and some dicoupled product $( \pm)-\mathbf{1 5 c}$ was also isolated from the reaction mixture. With HG-2 catalyst, $( \pm)-15 c$ was the main product, but an amount of $( \pm)-15 \mathbf{a}$ and $( \pm)-\mathbf{1 5 b}$ was formed as well. Judging from the ratio of ( \pm )-15a and $( \pm)$-15b, HG-2 catalyst was the most regioselective and G-3 was the least regioselective.

The next CM partner was 2,2,2-trifluoroethyl acrylate (7e, Scheme 9 and Table 9). With HG-2 catalyst, dimetathesized product $( \pm)$-16c was formed in medium yield, and some monometathesized product $( \pm)-\mathbf{1 6 a}$ was present too. With G-2 catalyst, the inseparable mixture of monometathesized compounds $( \pm)-\mathbf{1 6 a}$ and $( \pm)-\mathbf{1 6} \mathbf{b}$ (in 2.5:1 ratio) was the main product, accompanied with some $( \pm)-\mathbf{1 6 c}$. Only monometathesized products formed with G-3 catalyst, but both the yield and regioselectivity were inferior compared to those found with G-2.
CM reactions of substrate $( \pm)-\mathbf{5}$ and type I olefin $7 \mathbf{f}$ were studied only with HG-2 and G-2 catalysts, respectively (Scheme 10 and Table 10). In both cases, only a mixture of monocoupled products $( \pm)-\mathbf{1 7} \mathbf{a}$ and $( \pm)-\mathbf{1 7} \mathbf{b}$ was formed, which was separable. The main product was always $( \pm)-17 a$. HG-2 was more regioselective (ratio of $( \pm)-\mathbf{1 7 a}$ and $( \pm)-\mathbf{1 7 b}$ : $5: 1$ with HG-2 and 3.3:1 with G2), but G-2 provided a higher yield.

We also attempted CM reactions of ( \pm )-5 with 8-(allyloxy)1,1,1,2,2,3,3,4,4,5,5,6,6-tridecafluorooctane (7g, Scheme 11). However, dimetathesized product $( \pm)$-18c was not formed, and isolation of monometathesized products $( \pm$ )-18a and $( \pm$ )-18b (or a mixture thereof) in pure form failed despite repeated attempts of chromatographic separation.

Finally, isoxazoline ( \pm )-5 was subjected to CM with 4-fluorostyrene (7h, Scheme 12 and Table 11). HG-2 catalyst provided

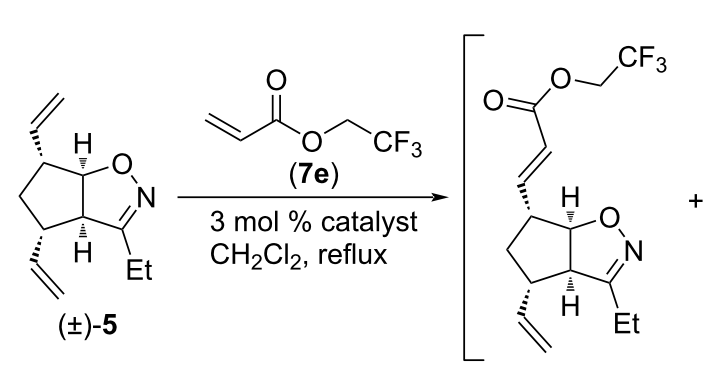

$( \pm)-16 a$ (major)

mixture of monometathesized products (selective with HG-2)<smiles>C=CC1CC(/C=C/C(=O)OCC(F)(F)F)C2C(C)CCC12</smiles>

( \pm -16b (minor)<smiles>CCC1=NO[C@H]2[C@H](/C=C/C(=O)OCC(F)(F)F)C[C@@H](/C=C/C(=O)OCC(F)(F)F)[C@H]12</smiles>

Scheme 9: Cross-metathesis of divinylated isoxazoline ( \pm )-5 with 2,2,2-trifluoroethyl acrylate (7e).

Table 9: CM of isoxazoline ( \pm )-5 with 2,2,2-trifluoroethyl acrylate (7e).

$\begin{array}{lllll}\text { entry } & \text { catalyst } & \text { reaction time } & \text { yield and ratio of }( \pm)-16 \mathbf{a} \text { and }( \pm)-16 b & 52 \% \\ 1 & \text { HG-2 } & 5 \mathrm{~h} & 7 \%(1: 0) & 0 \% \\ 2 & \text { G-3 } & 5 \mathrm{~h} & 25 \%(2: 1) & 8 \%\end{array}$




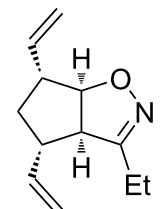

$( \pm)-5$

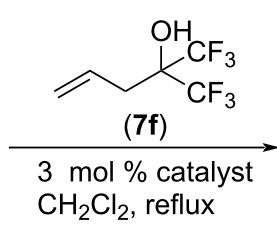

$\mathrm{CH}_{2} \mathrm{Cl}_{2}$, reflux<smiles>C=CC1CC(/C=C/CC(O)(F)F)C2ON=C(CC)C12</smiles>

$( \pm)-17 a$
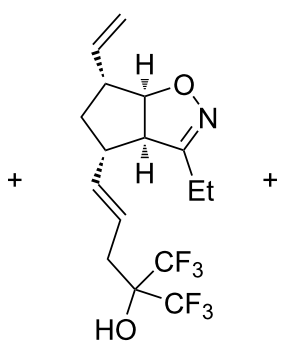

$( \pm)-17 b$

(minor)

separated monometathesized products<smiles>CCC1=NOC2C[C@H](/C=C/CC(O)(C(F)(F)F)C(F)(F)F)CC(/C=C/CC(O)(C(F)(F)F)C(F)(F)F)C12</smiles>

$( \pm)-17 c$

Scheme 10: Cross-metathesis of divinylated isoxazoline ( \pm )-5 with 1,1,1-trifluoro-2-(trifluoromethyl)pent-4-en-2-ol (7f).

Table 10: CM of isoxazoline ( \pm )-5 with 1,1,1-trifluoro-2-(trifluoromethyl)pent-4-en-2-ol (7f).

\begin{tabular}{llllll} 
entry & catalyst & reaction time & yield of $( \pm)-17 a$ & yield of $( \pm)-17 b$ & yield of $( \pm)-17 c$ \\
\hline 1 & HG-2 & $5 \mathrm{~h}$ & $21 \%$ & $4 \%$ & $0 \%$ \\
2 & G-2 & $5 \mathrm{~h}$ & $34 \%$ & $11 \%$ & $0 \%$
\end{tabular}

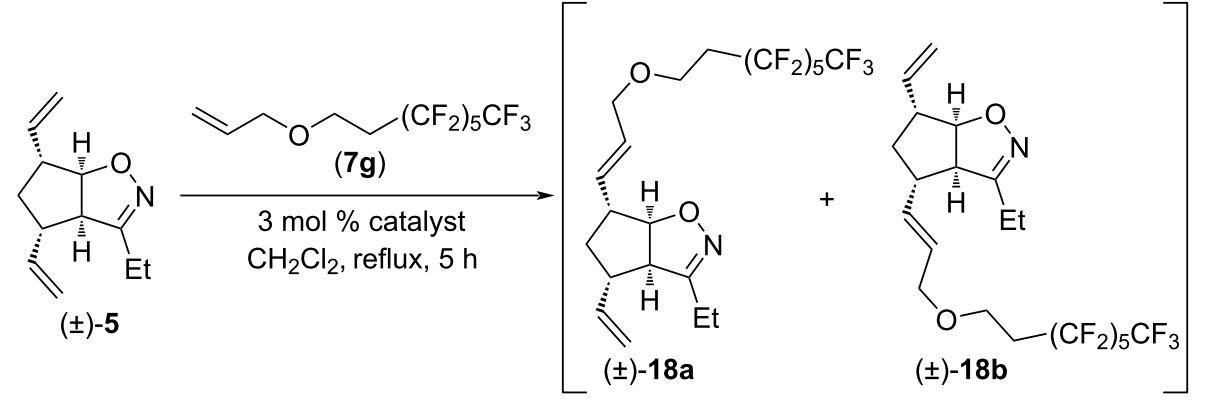

mixture of unindentifiable monometathesized products

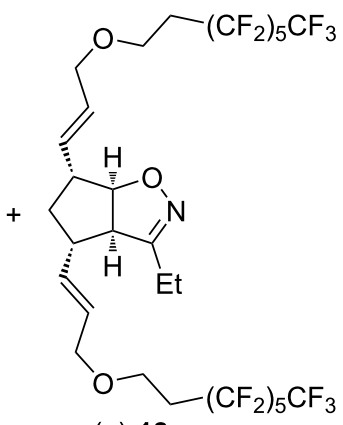

$( \pm)-18 c$

Scheme 11: Cross-metathesis of divinylated isoxazoline ( \pm )-5 with 8-(allyloxy)-1,1,1,2,2,3,3,4,4,5,5,6,6-tridecafluorooctane (7g).

mainly dicoupled product $( \pm)-19 c$, but some amount of $( \pm)-19 a$ and ( \pm )-19b mixture was isolated too. G-3 catalyst provided mainly the inseparable mixture of monocoupled products $( \pm)-19 a$ and $( \pm)-19 b$, but some $( \pm)-19 c$ was formed as well. With G-2 catalyst, a product mixture of $( \pm)-\mathbf{1 9 a}$ and $( \pm)-\mathbf{1 9 b}$ was formed in slightly higher yield than with G-3, but it was accompanied with a considerable amount of $( \pm)-19 c$. With all three catalysts, the ratio of $( \pm)-\mathbf{1 9 a}$ and $( \pm)-\mathbf{1 9 b}$ was $2: 1$.

We continued our work with the study of CM reactions of phenyl-substituted isoxazoline ( \pm )-6. Similar to $( \pm)-4$ and $( \pm)-5$, no $\mathrm{CM}$ product was observed with olefins $\mathbf{7 a}$ and $\mathbf{7 b}$. However, $\mathrm{CM}$ reactions with $\mathbf{7 c}$ were successful (Scheme 13 and Table 12). With HG-2 catalyst, dimetathesized compound
$( \pm)$-20c was the main product and monometathesized compound ( \pm -20a was the minor product. With G-2 catalyst, that preference was reversed. G-3 catalyst provided product ( \pm )-20a in an exclusive manner, and this was the most efficient way to synthesize this monometathesized compound. Importantly, formation of alternative monometathesized product $( \pm)$-20b was not observed.

Then, CM reactions of ( \pm )-6 with alkene $\mathbf{7 d}$ were explored (Scheme 14 and Table 13). G-3 catalyst yielded ( \pm )-21a as the sole monocoupled product, while HG-2 and G-2 catalysts gave both monocoupled $( \pm)-21 a$ and dicoupled $( \pm)$-21c. The best yield of $( \pm)$-21c was achieved with HG-2 catalyst (although G-2 catalyst also produced a surprisingly high amount 


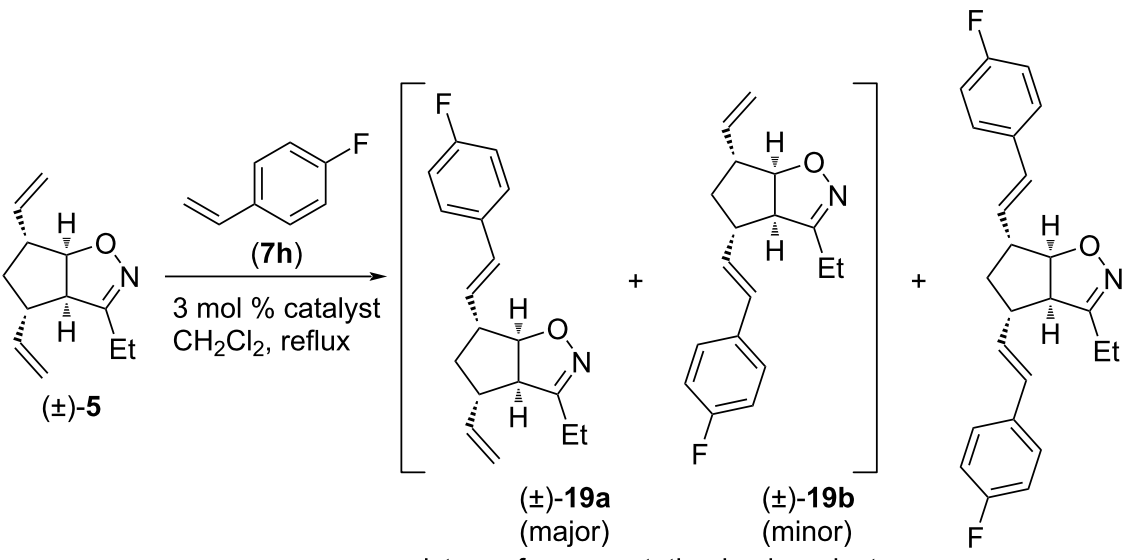

mixture of monometathesized products

$( \pm)-19 c$

Scheme 12: Cross-metathesis of divinylated isoxazoline ( \pm )-5 with 4-fluorostyrene (7h).

Table 11: CM of isoxazoline $( \pm)-5$ with 4-fluorostyrene $(7 \mathrm{~h})$.

\begin{tabular}{lllll} 
entry & catalyst & reaction time & yield and ratio of $( \pm)-19 a$ and $( \pm)-19 b$ & yield of $( \pm)$-19c \\
\hline 1 & HG-2 & $5 \mathrm{~h}$ & $12 \%(2: 1)$ & $38 \%$ \\
2 & G-3 & $5 \mathrm{~h}$ & $35 \%(2: 1)$ & $7 \%$ \\
3 & G-2 & $5 \mathrm{~h}$ & $37 \%(2: 1)$ & $22 \%$
\end{tabular}<smiles>C=CC1CC(C=C)C2C(c3ccccc3)=NOC12</smiles>

$( \pm)-6$

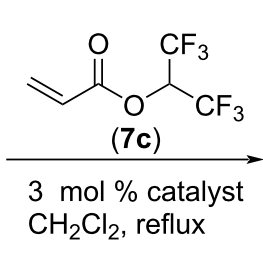

$3 \mathrm{~mol} \%$ catalyst

$\mathrm{Cl}_{2}$, reflux<smiles>C=CC1CC(/C=C/C(=O)OC(C(F)(F)F)C(F)(F)F)C2ON=C(c3ccccc3)C12</smiles>

$( \pm)-20 a$<smiles>C=CC1CC(/C=C/C(=O)OC(F)(F)F)C2C(c3ccccc3)NOC12</smiles>

( \pm )-20b<smiles>O=C(/C=C/[C@H]1C[C@H](/C=C/C(=O)C(F)(F)C(F)(F)F)[C@H]2C(c3ccccc3)=NO[C@H]21)OC(C(F)(F)F)C(F)(F)F</smiles>

(士)-20c

selective $\mathrm{CM}$ reaction, only a single monometathesized product was formed

Scheme 13: Cross-metathesis of divinylated isoxazoline ( \pm )-6 with 1,1,1,3,3,3-hexafluoropropan-2-yl acrylate (7c).

Table 12: CM of isoxazoline ( \pm )-6 with 1,1,1,3,3,3-hexafluoropropan-2-yl acrylate (7c).

$\begin{array}{lllll}\text { entry } & \text { catalyst } & \text { reaction time } & \text { yield and ratio of }( \pm)-20 \mathbf{a} \text { and }( \pm)-20 b & \text { yield of }( \pm)-20 c \\ 1 & \text { HG-2 } & 5 \mathrm{~h} & 6 \%(1: 0) & 38 \% \\ 2 & \text { G-3 } & 5 \mathrm{~h} & 30 \%(1: 0) & 0 \% \\ 3 & \text { G-2 } & 5 \mathrm{~h} & 16 \%(1: 0) & 7 \%\end{array}$




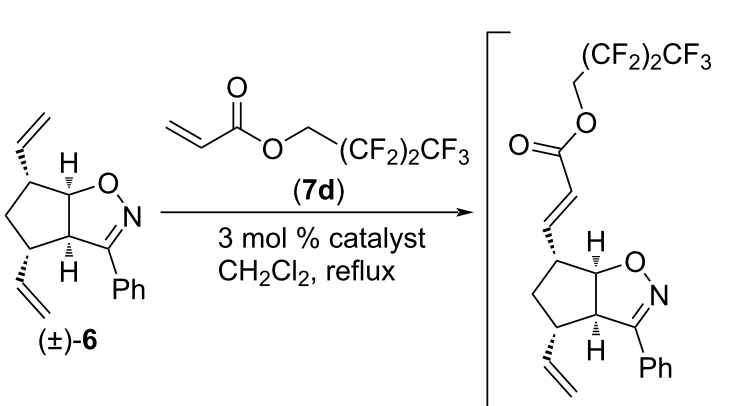

(士)-21a<smiles>C=CC1CC(/C=C/C(=O)OCC(F)(F)F)C2C(c3ccccc3)NOC12</smiles>

$( \pm)-21 b$<smiles>O=C(/C=C/[C@H]1C[C@H](/C=C/C(=O)OCC(F)(F)C(F)(F)F)[C@H](c2ccccc2)[C@H]1/C=C/C(=O)OCC(F)(F)C(F)(F)F)OCC(F)(F)C(F)(F)F</smiles>

( \pm -21c

selective $\mathrm{CM}$ reaction, a single monometathesized product was formed

Scheme 14: Cross-metathesis of divinylated isoxazoline ( \pm )-6 with 2,2,3,3,4,4,4-heptafluorobutyl acrylate (7d).

Table 13: CM of isoxazoline ( \pm )-6 with 2,2,3,3,4,4,4-heptafluorobutyl acrylate (7d).

\begin{tabular}{lllll} 
entry & catalyst & reaction time & yield and ratio of $( \pm)-21 a$ and $( \pm)-21 b$ & $37 \%$ \\
\hline 1 & HG-2 & $5 \mathrm{~h}$ & $18 \%(1: 0)$ & $0 \%$ \\
3 & G-3 & $5 \mathrm{~h}$ & $17 \%(1: 0)$ & $32 \%$
\end{tabular}

of $( \pm)-21 c)$, while the synthesis of $( \pm)-21$ a was the most efficient with G-2 catalyst. Note, that this CM reaction was also regioselective.

CM reactions of compound ( \pm )-6 with olefin 7 e were also regioselective (Scheme 15 and Table 14). G-3 catalyst yielded only monometathesized $( \pm)-\mathbf{2 2} \mathbf{a}$ as a single product, HG-2 catalyst gave mainly dimetathesized $( \pm)-22 c$ (together with some $( \pm)-22 a)$ and G-2 catalyst gave mainly monometathesized
$( \pm)-22 a$ (together with some $( \pm)-22 c)$. The best yield of $( \pm)-22 c$ was achieved with HG-2 catalyst, while the synthesis of $( \pm)-\mathbf{2 2 a}$ was the most efficient with G-2 catalyst.

Cross metathesis of substrate $( \pm)-6$ with unsaturated alcohol 7f was also performed (Scheme 16 and Table 15). The reaction was completely regioselective with HG-2 and G-2 catalysts, and provided only a single monocoupled product, $( \pm)-\mathbf{2 3 a}$. The best yield was achieved with G-2 catalyst.

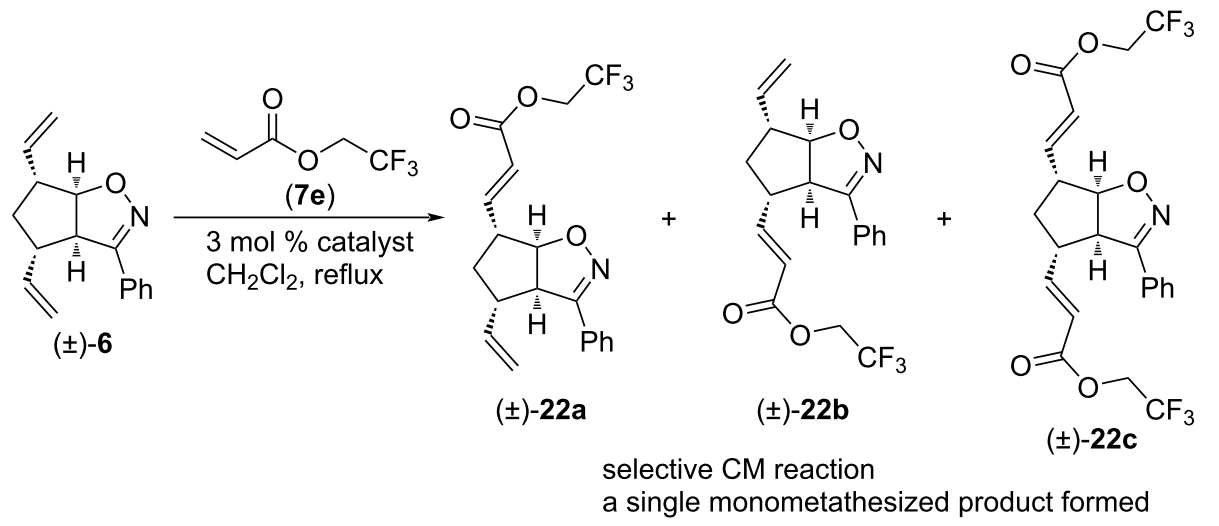

Scheme 15: Cross-metathesis of divinylated isoxazoline ( \pm )-6 with 2,2,2-trifluoroethyl acrylate (7e). 
Table 14: $\mathrm{CM}$ of isoxazoline ( \pm )-6 with 2,2,2-trifluoroethyl acrylate (7e).

\begin{tabular}{lllll} 
entry & catalyst & reaction time & yield and ratio of $( \pm)-22 a$ and $( \pm)-22 b$ & $48 \%$ \\
\hline 1 & HG-2 & $5 \mathrm{~h}$ & $4 \%(1: 0)$ & $0 \%$ \\
2 & G-3 & $5 \mathrm{~h}$ & $22 \%(1: 0)$ & $11 \%$ \\
3 & G-2 & $5 \mathrm{~h}$ & $37 \%(1: 0)$ &
\end{tabular}

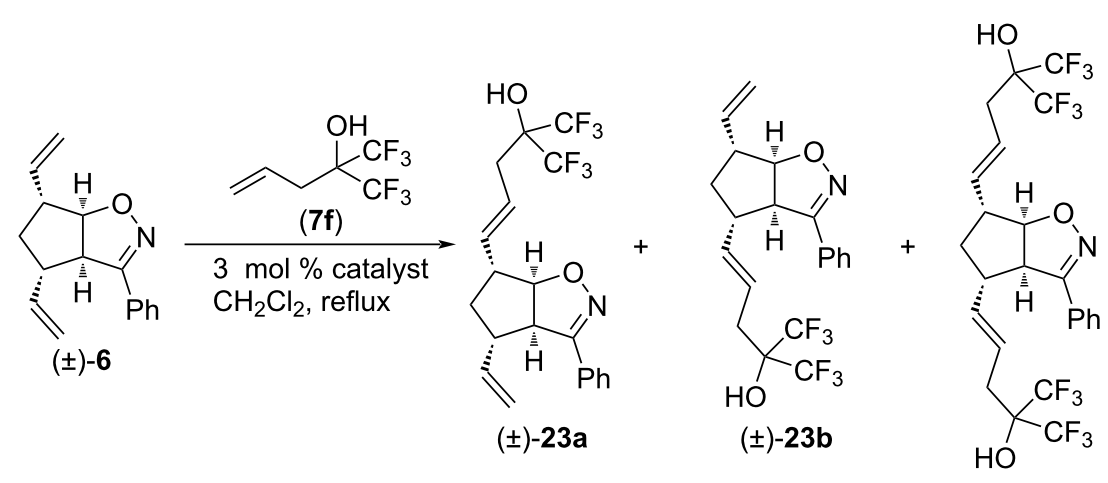

selective $\mathrm{CM}$ reaction, a single

$( \pm)-23 c$ monometathesized product was formed

Scheme 16: Cross-metathesis of divinylated isoxazoline ( \pm )-6 with 1,1,1-trifluoro-2-(trifluoromethyl)pent-4-en-2-ol (7f).

Table 15: CM of isoxazoline ( \pm )-6 with 1,1,1-trifluoro-2-(trifluoromethyl)pent-4-en-2-ol (7f).

\begin{tabular}{lllll} 
entry & catalyst & reaction time & yield and ratio of $( \pm)-23 \mathbf{a}$ and $( \pm)-23 b$ & $0 \%$ \\
\hline 1 & HG-2 & $5 \mathrm{~h}$ & $3 \%(1: 0)$ & $0 \%$
\end{tabular}

We also attempted CM reactions of ( \pm )-6 with 8-(allyloxy)- $\quad$ isolation of monometathesized products $( \pm$ )-24a and ( \pm )-24b (or 1,1,1,2,2,3,3,4,4,5,5,6,6-tridecafluorooctane (7g, Scheme 17). a mixture thereof) in pure form failed, despite repeated attempts However, dimetathesized product $( \pm)-\mathbf{2 4 c}$ was not formed, and of chromatographic separation.

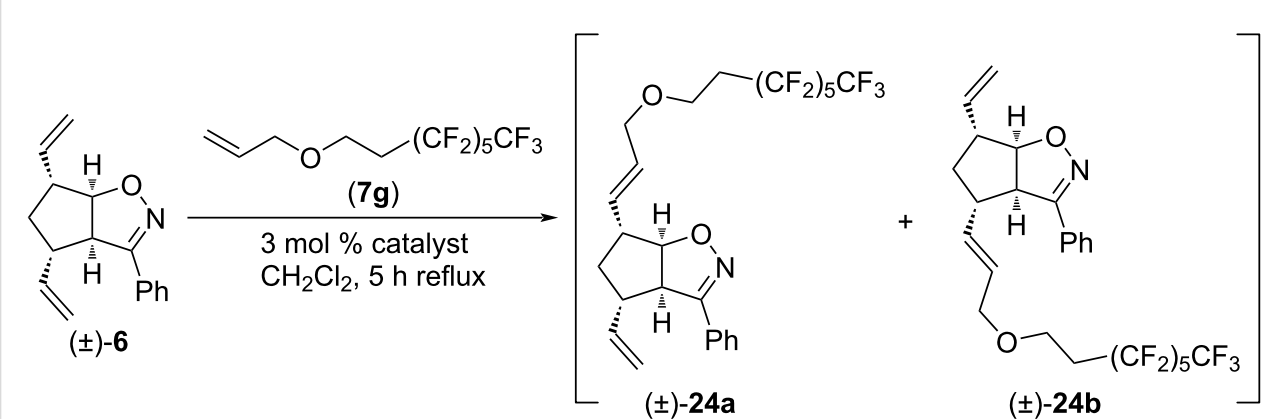

mixture of unindentifiable monometathesized products

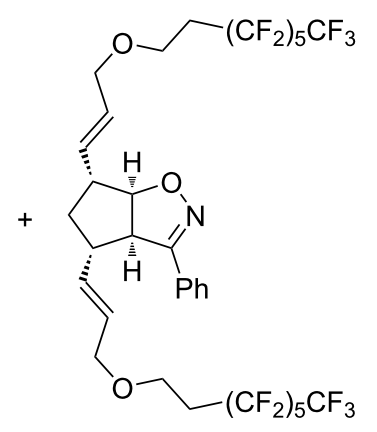

$( \pm)-24 c$ 
Finally, CM reactions between isoxazoline ( \pm )-6 and 4-fluorostyrene (7h) were studied (Scheme 18 and Table 16). HG-2 catalyst provided monocoupled ( \pm )-25a and dicoupled $( \pm)$-25c in a comparable amount. With G-2 catalyst, both products were formed in higher yield. G-3 catalyst provided mostly monocoupled ( \pm )-25a, but a low amount of $( \pm)-25 \mathrm{c}$ was also isolated. Note, that the CM reaction was highly regioselective (alternative monocoupled product ( \pm )-25b was not detected).

\section{Conclusion}

An insight into the study of selective functionalization of norbornadiene through nitrile oxide 1,3-dipolar cycloaddition/ $\mathrm{ROM} / \mathrm{CM}$ strategies was presented. The stepwise functionalization of norbornadiene across the ring olefin bonds generated fluorine-containing alkenylated cyclopentane-fused isoxazolines. The synthetic protocol was based on selective nitrile oxide cycloaddition to the norbornadiene $\mathrm{C}=\mathrm{C}$ bond, followed by ROM of the resulting cyclopentane-fused isoxazolines. In the final step, selective CM by chemodifferentiation of the newly created olefin bonds on the resulting alkenylated derivatives took place. As coupling olefin partners in CM reactions, several commercial fluorine-containing alkenes have been investigated (type I and type II), and CM has been studied in order to explore the substrate effect, catalyst influence and the chemical behavior of the olefin bonds. Second-generation Ru-based commercial catalysts G-2 and HG-2 as well as thirdgeneration G-3 were found to be more effective in the CM transformations. Note, that first-generation catalyst HG-1 did not afford cross-metathesized products.

Our data allows to summarize some clearly visible general trends. First of all, most CM reactions of compounds ( \pm )-4 and $( \pm)-5$ were only slightly regioselective (transformation of the vinyl group at C-6 was preferred, except for the reactions of isoxazoline ( \pm )-4 with $\mathbf{7 f}$ and $\mathbf{7 g}$ ), while all $\mathrm{CM}$ reactions of $( \pm)-6$ were completely regioselective (the vinyl group at C-6 was transformed first). This can be explained by steric hindrance: the substituent at C-3 on the isoxazoline ring shields the vinyl group at C-4 from reacting with the bulky catalyst molecules (Figure 4). For the smaller Me or Et groups, this effect is relatively weak (only some reactions of $( \pm$ )-5 with $7 \mathbf{c}$ and 7e were completely regioselective). The large $\mathrm{Ph}$ group, however, provided complete regioselectivity in all successful $\mathrm{CM}$ reactions.

The ratio of monometathesized products in $\mathrm{CM}$ reactions of $( \pm)-4$ and $( \pm)-5$ also depended on the catalyst. Generally, HG-2 catalyst provided the highest regioselectivity. Unfortunately,

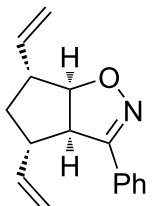

$( \pm)-6$

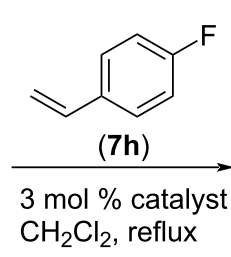

7h)

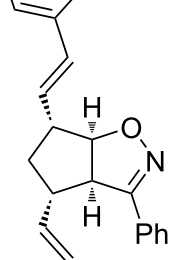

$( \pm)-25$<smiles>C=CC1CC(/C=C/c2ccc(F)cc2)C2C(c3ccccc3)=NOC12</smiles>

$( \pm)-25 b$

selective $\mathrm{CM}$ reaction, a single monometathesized product was formed

Scheme 18: Cross-metathesis of divinylated isoxazoline ( \pm )-6 with 4-fluorostyrene $(7 \mathrm{~h})$.

Table 16: $\mathrm{CM}$ of isoxazoline ( \pm )-6 with 4-fluorostyrene (7h).

$\begin{array}{lllll}\text { entry } & \text { catalyst } & \text { reaction time } & \text { yield and ratio of }( \pm)-25 a \text { and }( \pm)-25 b \quad 18 \%(1: 0) & 25 \% \\ 1 & \text { HG-2 } & 5 \mathrm{~h} & 18 \%(1: 0) & 2 \% \\ 2 & \text { G-3 } & 5 \mathrm{~h} & 28 \%(1: 0) & 49 \%\end{array}$




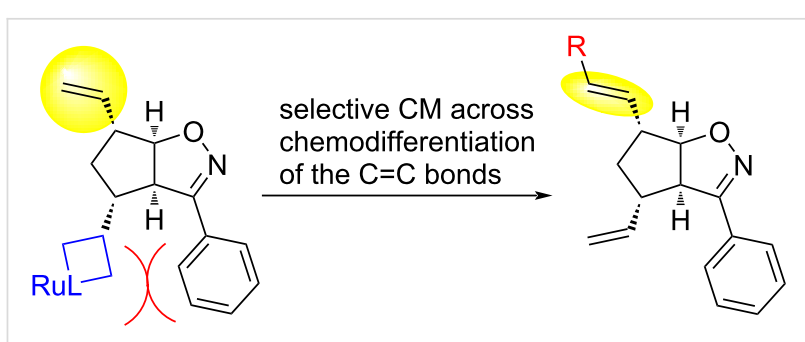

Figure 4: Chemoselective $\mathrm{CM}$ reaction due to steric hindrance.

separation of regioisomeric monometathesized compounds proved to be impossible in most cases (only monocoupled products with olefins $\mathbf{7 f}$ and $\mathbf{7 g}$ were separable). However, the formed dimetathesized products could be separated from the monometathesized compounds.

Usually, the best (combined) yield of monometathesized products was achieved with G-2 catalyst, while HG-2 provided the best yield of dicoupled products. Notably, G-3 catalyst highly disfavored the formation of dimetathesized products.

Further investigations in view of the selectivity of CM reactions with other novel model compounds as well as further functionalization strategies are currently being investigated in our group.

\section{Supporting Information}

\section{Supporting Information File 1}

Experimental section and NMR spectra.

[https://www.beilstein-journals.org/bjoc/content/

supplementary/1860-5397-17-132-S1.pdf]

\section{Funding}

We are grateful to the Hungarian Research Foundation (NKFIH $\mathrm{K}$ 119282) for financial support. The financial support of the GINOP-2.3.2-15-2016-00038 project is also acknowledged. This research was supported by the EU-funded Hungarian grant EFOP-3.6.1-16-2016-00008. The Ministry of Human Capacities, Hungary (grant 20391-3/2018/FEKUSTRAT) is also acknowledged. This work was supported by the ÚNKP-20-3 New National Excellence Program of the Ministry for Innovation and Technology from the source of the National Research, Development and Innovation Fund.

\section{References}

1. Grela, K. Olefin Metathesis; Theory and Practice; John Wiley \& Sons: Hoboken, NJ, USA, 2014. doi:10.1002/9781118711613
2. Kotha, S.; Dipak, M. K. Tetrahedron 2012, 68, 397-421. doi:10.1016/j.tet.2011.10.018

3. Trnka, T. M.; Grubbs, R. H. Acc. Chem. Res. 2001, 34, 18-29. doi:10.1021/ar000114f

4. Kress, S.; Blechert, S. Chem. Soc. Rev. 2012, 41, 4389. doi:10.1039/c2cs15348c

5. Lee, H.-K.; Lee, J.; Kockelmann, J.; Herrmann, T.; Sarif, M.; Choi, T.-L. J. Am. Chem. Soc. 2018, 140, 10536-10545. doi:10.1021/jacs.8b05613

6. Lecourt, C.; Dhambri, S.; Allievi, L.; Sanogo, Y.; Zeghbib, N.; Ben Othman, R.; Lannou, M.-I.; Sorin, G.; Ardisson, J. Nat. Prod. Rep. 2018, 35, 105-124. doi:10.1039/c7np00048k

7. Park, H.; Lee, H.-K.; Choi, T.-L. J. Am. Chem. Soc. 2013, 135 , 10769-10775. doi:10.1021/ja4039278

8. Vougioukalakis, G. C. Chem. - Eur. J. 2012, 18, 8868-8880. doi:10.1002/chem.201200600

9. Gutiérrez-Loriente, A.; Martín-Álvarez, J. M.; Prieto, E.; Andrés, C.; Nieto, J. Adv. Synth. Catal. 2019, 361, 1042-1063. doi:10.1002/adsc.201801454

10. Groso, E. J.; Schindler, C. S. Synthesis 2019, 51, 1100-1114. doi:10.1055/s-0037-1611651

11. Sánchez-Roselló, M.; Miró, J.; del Pozo, C. Synthesis 2017, 49, 2787-2802. doi:10.1055/s-0036-1589497

12. Cheng-Sánchez, I.; Sarabia, F. Synthesis 2018, 50, 3749-3786. doi:10.1055/s-0037-1610206

13. Felpin, F.-X.; Lebreton, J. Eur. J. Org. Chem. 2003, 3693-3712. doi:10.1002/ejoc.200300193

14. Sauer, D. F.; Schiffels, J.; Hayashi, T.; Schwaneberg, U.; Okuda, J. Beilstein J. Org. Chem. 2018, 14, 2861-2871. doi:10.3762/bjoc.14.265

15. Gleeson, E. C.; Jackson, W. R.; Robinson, A. J. Tetrahedron Lett. 2016, 57, 4325-4333. doi:10.1016/j.tetlet.2016.08.032

16. Kiss, L.; Kardos, M.; Vass, C.; Fülöp, F. Synthesis 2018, 50, 3571-3588. doi:10.1055/s-0036-1591600

17. Brik, A. Adv. Synth. Catal. 2008, 350, 1661-1675. doi:10.1002/adsc.200800149

18. Kotha, S.; Goyal, D.; Chavan, A. S. J. Org. Chem. 2013, 78, 12288-12313. doi:10.1021/jo4020722

19. Glas, A.; Grossmann, T. N. Synlett 2015, 26, 1-5 doi:10.1055/s-0034-1379425

20. Fustero, S.; Mateu, N.; Simón-Fuentes, A.; Aceña, J. L. Org. Lett. 2010, 12, 3014-3017. doi:10.1021/ol1010246

21. Yu, M.; Lou, S.; Gonzalez-Bobes, F. Org. Process Res. Dev. 2018, 22 , 918-946. doi:10.1021/acs.oprd.8b00093

22. Ogba, O. M.; Warner, N. C.; O’Leary, D. J.; Grubbs, R. H. Chem. Soc. Rev. 2018, 47, 4510-4544. doi:10.1039/c8cs00027a

23. Hoveyda, A. H.; Liu, Z.; Qin, C.; Koengeter, T.; Mu, Y. Angew. Chem., Int. Ed. 2020, 59, 22324-22348. doi:10.1002/anie.202010205

24. Wolf, W. J.; Lin, T.-P.; Grubbs, R. H. J. Am. Chem. Soc. 2019, 141, 17796-17808. doi:10.1021/jacs.9b08835

25. Hyatt, M. G.; Walsh, D. J.; Lord, R. L.; Andino Martinez, J. G.; Guironnet, D. J. Am. Chem. Soc. 2019, 141, 17918-17925. doi:10.1021/jacs.9b09752

26. Yasir, M.; Liu, P.; Markwart, J. C.; Suraeva, O.; Wurm, F. R.; Smart, J.; Lattuada, M.; Kilbinger, A. F. M. Angew. Chem., Int. Ed. 2020, 59, 13597-13601. doi:10.1002/anie.202005366

27. Datta, R.; Ghosh, S. Beilstein J. Org. Chem. 2018, 14, 2708-2714. doi:10.3762/bjoc. 14.248

28. Li, C.; Liu, L.; Fu, X.; Huang, J. Synthesis 2018, 50, 2799-2823. doi:10.1055/s-0037-1610143 
29. Montgomery, T. P.; Ahmed, T. S.; Grubbs, R. H. Angew. Chem., Int. Ed. 2017, 56, 11024-11036. doi:10.1002/anie.201704686

30. Bidange, J.; Fischmeister, C.; Bruneau, C. Chem. - Eur. J. 2016, 22 , 12226-12244. doi:10.1002/chem.201601052

31. Kiss, L.; Kardos, M.; Forró, E.; Fülöp, F. Eur. J. Org. Chem. 2015, 1283-1289. doi:10.1002/ejoc.201403493

32. Kardos, M.; Kiss, L.; Fülöp, F. Asian J. Org. Chem. 2015, 4, 1155-1159. doi:10.1002/ajoc.201500286

33. Benke, Z.; Nonn, M.; Kardos, M.; Fustero, S.; Kiss, L. Beilstein J. Org. Chem. 2018, 14, 2698-2707. doi:10.3762/bjoc.14.247

34. Henderson, J. A.; Phillips, A. J. Angew. Chem., Int. Ed. 2008, 47, 8499-8501. doi:10.1002/anie.200803593

35. Hoveyda, A. H.; Lombardi, P. J.; O'Brien, R. V.; Zhugralin, A. R. J. Am. Chem. Soc. 2009, 131, 8378-8379. doi:10.1021/ja9030903

36. Kardos, M.; Kiss, L.; Haukka, M.; Fustero, S.; Fülöp, F. Eur. J. Org. Chem. 2017, 1894-1901. doi:10.1002/ejoc.201700064

37. Connon, S. J.; Blechert, S. Angew. Chem., Int. Ed. 2003, 42, 1900-1923. doi:10.1002/anie.200200556

38. Nolan, S. P.; Clavier, H. Chem. Soc. Rev. 2010, 39, 3305. doi:10.1039/b912410c

39. Nonn, M.; Benke, Z.; Fustero, S.; Fülöp, F.; Kiss, L. Eur. J. Org. Chem. 2019, 5285-5293. doi:10.1002/ejoc.201900101

40. Kiss, L.; Benke, Z.; Remete, A. M.; Fülöp, F. Chem. Rec. 2020, 20 , 1129-1141. doi:10.1002/tcr.202000070

41. Benke, Z.; Remete, A. M.; Semghouli, A.; Kiss, L. Asian J. Org. Chem. 2021, 10, 1184-1191. doi:10.1002/ajoc.202100147

42. Hartung, J.; Grubbs, R. H. J. Am. Chem. Soc. 2013, 135, 10183-10185. doi:10.1021/ja4046422

43. Koh, M. J.; Khan, R. K. M.; Torker, S.; Hoveyda, A. H. Angew. Chem., Int. Ed. 2014, 53, 1968-1972. doi:10.1002/anie.201309430

44. Chatterjee, A. K.; Choi, T.-L.; Sanders, D. P.; Grubbs, R. H. J. Am. Chem. Soc. 2003, 125, 11360-11370. doi:10.1021/ja0214882

45. Han, J.; Kiss, L.; Mei, H.; Remete, A. M.; Ponikvar-Svet, M.; Sedgwick, D. M.; Roman, R.; Fustero, S.; Moriwaki, H.; Soloshonok, V. A. Chem. Rev. 2021, 121, 4678-4742. doi:10.1021/acs.chemrev.0c01263

46. Han, J.; Remete, A. M.; Dobson, L. S.; Kiss, L.; Izawa, K.; Moriwaki, H.; Soloshonok, V. A.; O'Hagan, D. J. Fluorine Chem. 2020, 239, 109639. doi:10.1016/j.jfluchem.2020.109639

47. Zhou, Y.; Wang, J.; Gu, Z.; Wang, S.; Zhu, W.; Aceña, J. L.; Soloshonok, V. A.; Izawa, K.; Liu, H. Chem. Rev. 2016, 116, 422-518. doi:10.1021/acs.chemrev.5b00392

48. Wang, J.; Sánchez-Roselló, M.; Aceña, J. L.; del Pozo, C.; Sorochinsky, A. E.; Fustero, S.; Soloshonok, V. A.; Liu, H. Chem. Rev. 2014, 114, 2432-2506. doi:10.1021/cr4002879

49. Mei, H.; Han, J.; White, S.; Graham, D. J.; Izawa, K.; Sato, T.; Fustero, S.; Meanwell, N. A.; Soloshonok, V. A. Chem. - Eur. J. 2020, 26, 11349-11390. doi:10.1002/chem.202000617

50. Kiss, L.; Ouchakour, L.; Ábrahámi, R. A.; Nonn, M. Chem. Rec. 2020, 20, 120-141. doi:10.1002/tcr.201900025

51. Remete, A. M.; Nonn, M.; Fustero, S.; Fülöp, F.; Kiss, L. Tetrahedron 2018, 74, 6367-6418. doi:10.1016/j.tet.2018.09.021

52. Ni, C.; Hu, J. Chem. Soc. Rev. 2016, 45, 5441-5454. doi:10.1039/c6cs00351f

53. Yerien, D. E.; Bonesi, S.; Postigo, A. Org. Biomol. Chem. 2016, 14, 8398-8427. doi:10.1039/c6ob00764c

54. Yin, G.; Mu, X.; Liu, G. Acc. Chem. Res. 2016, 49, $2413-2423$. doi:10.1021/acs.accounts.6b00328
55. Caron, S. Org. Process Res. Dev. 2020, 24, 470-480. doi:10.1021/acs.oprd.0c00030

56. Liao, J.; Ouyang, L.; Lai, Y.; Luo, R. J. Org. Chem. 2020, 85, 5590-5597. doi:10.1021/acs.joc.0c00457

57. Hirano, K.; Saito, T.; Fujihira, Y.; Sedgwick, D. M.; Fustero, S.; Shibata, N. J. Org. Chem. 2020, 85, 7976-7985. doi:10.1021/acs.joc.0c00796

58. He, Y.; Yang, Z.; Thornbury, R. T.; Toste, F. D. J. Am. Chem. Soc. 2015, 137, 12207-12210. doi:10.1021/jacs.5b07795

59. Fustero, S.; Simón-Fuentes, A.; Barrio, P.; Haufe, G. Chem. Rev. 2015, 115, 871-930. doi:10.1021/cr500182a

\section{License and Terms}

This is an Open Access article under the terms of the Creative Commons Attribution License (https://creativecommons.org/licenses/by/4.0). Please note that the reuse, redistribution and reproduction in particular requires that the author(s) and source are credited and that individual graphics may be subject to special legal provisions.

The license is subject to the Beilstein Journal of Organic Chemistry terms and conditions: (https://www.beilstein-journals.org/bjoc/terms)

The definitive version of this article is the electronic one which can be found at: https://doi.org/10.3762/bjoc. 17.132 